\title{
Research
}

Vicente Gil-Guillén, Enrique Hermida, Salvador Pita-Fernandez, Antonio Palazon-Bru, Ramon Durazo-Arvizu, Vicente Pallares-Carratala, Domingo Orozco-Beltran,

Concepcion Carratala-Munuera, Adriana Lopez-Pineda and Jorge Navarro

\section{A cardiovascular educational intervention for primary care professionals in Spain:}

\author{
positive impact in a quasi-experimental study
}

\begin{abstract}
\section{Background}

Routine general practice data collection can

help identify patients at risk of cardiovascular disease.
\end{abstract}

\section{Aim}

To determine whether a training programme for primary care professionals improves the recording of cardiovascular disease risk factors in electronic health records.

\section{Design and setting}

A quasi-experimental study without random assignment of professionals. This was an educational intervention study, consisting of an online-classroom 1-year training programme, and carried out in the Valencian community in Spain

\section{Method}

The prevalence rates of recording of cardiovascular factors (recorded every 6 months over a 4-year period) were compared between intervention and control group. Clinical relevance was calculated by absolute risk reduction (ARR), relative risk reduction (RRR), and number of patients needed-to-attend (NNA), to avoid under-recording, with their 95\% confidence intervals (Cls). Linear regression models were used for each of the variables.

\section{Results}

Of the 941 professionals initially registered, $78.1 \%$ completed the programme. The ARR ranged from $1.87 \%(95 \% \mathrm{Cl}=1.79$ to 1.94$)$ in the diagnosis of diabetes to $15.27 \%(95 \% \mathrm{Cl}=15.14$ to 15.40 ) in the recording of basal blood glucose. The NNA ranged from 7 in blood pressure. cholesterol, and blood glucose recording to 54 in the diagnosis of diabetes. The RRR ranged from $26.7 \%$ in the diagnosis of diabetes to $177.1 \%$ in the recording of the Systematic Coronary Risk Evaluation (SCORE). The rates of change were greater in the intervention group and the differences were significant for recording of cholesterol $(P<0.001)$, basal blood glucose $(P<0.001)$, smoking $(P<0.001)$, alcohol $(P<0.001)$, microalbuminuria $(P=0.001)$, abdominal circumference $(P<0.001)$, and SCORE $(P<0.001)$.

\section{Conclusion}

The education programme had a beneficial effect at the end of the follow-up that was significant and clinically relevant.

\section{Keywords}

cardiovascular diseases; health education; prevention and control; registries.

\section{INTRODUCTION}

The volume of new information in the cardiovascular field and the speed at which this appears requires continuous training for physicians to stay up-to-date and make the best clinical decisions. ${ }^{1}$ Participation by physicians in training programmes improves their clinical awareness and application of new evidence-based knowledge. ${ }^{2}$ The 21 st century physician should understand clinical epidemiology, information technology, and healthcare guidelines to minimise uncertainties in the diagnostic and therapeutic processes. ${ }^{3}$ In Spain instruments are being integrated in the health services' electronic health records (EHRs) with experience-based postgraduate training programmes, such as the ESCARVAL project. ${ }^{4}$

Application of new technologies in the field of health sciences has resulted in the internet being used by many healthcare professionals and providers of further education to offer the most up-to-date training in decision making. Online education should be based on the guidelines for best clinical practice and provide an alternative that complements traditional training programmes. ${ }^{5}$ Internet- based learning is just as useful as face-toface training and may be very effective at improving clinical practice. ${ }^{6-10}$

The high mortality rate associated with cardiovascular diseases and the high population prevalence of risk factors such as hypertension, smoking, obesity, physical inactivity, dyslipidaemia, and diabetes mellitus ${ }^{11}$ are primary topics in all healthcare strategy plans. ${ }^{12}$ Consensus agreements recommend establishing strategies to detect and manage risk factors in the earliest stages. This early identification will reduce the likelihood of patients experiencing events, improve the quality of life in society, and reduce social and healthcare expenditure., 1,3,13,14 The detection and diagnosis of risk factors in their very early stages, together with the systematic implantation in clinical practice of preventive activities, are key to achieving a reduction in cardiovascular diseases. This requires training for healthcare professionals in their application. In Spain, preventive activities should undoubtedly be undertaken by primary care teams (nurses and physicians) $)^{1,15}$ because these are the people closest to the patients and in a 1 -year period over $90 \%$ of the population
V Gil-Guillén, PhD, professor of clinical medicine E Hermida, PhD, research assistant;

A Palazon-Bru, PhD, biostatistician and medical

writer; D Orozco-Beltran, PhD, assistant professor of primary health care research;

C Carratala-Munuera, PhD, assistant professor of primary health care research; A Lopez-Pineda, MSc, research assistant, Clinical Medicine Department, Miguel Hernández University, San Juan de Alicante, Alicante, Spain.

S Pita-Fernandez, PhD, director, Clinical Epidemiology and Biostatistics Unit, Complexo Hospitalario Universitario A Coruña (CHUAC) SERGAS, Universidad de A Coruña, A Coruña, Spain. R Durazo-Arvizu, PhD, professor of public health sciences, Department of Biostatistics, School of Public Health, University of Alabama at Birmingham, Birmingham, AL, US.

V Pallares-Carratala, PhD, manager, Health
Surveillance Unit, Unión de Mutuas, Castellón, Spain. J Navarro, PhD, assistant professor of primary health care, Valencia University, Valencia, Spain.

\section{Address for correspondence}

Vicente Gil-Guillén, Clinical Medicine Department, Miguel Hernández University, Carretera Nacional 332 Alicante-Valencia s/n 03550, San Juan de Alicante, Spain.

E-mail: vte_gildgmail.com

Submitted: 14 January 2014; Editor's response: 1 April 2014; final acceptance: 30 May 2014 (B) British Journal of General Practice This is the full-length article (published online 29 Dec 2014) of an abridged version published in print. Cite this article as: Br J Gen Pract 2015; DOI: 10.3399/bjgp15X683137 


\section{How this fits in}

It is known that educational strategies for professional development should be continuous and permanent, and that detection and control of risk factors are key to achieving a reduction in cardiovascular diseases. This study demonstrated the efficacy of an educational intervention to improve cardiovascular risk factors screening by primary health professionals.

attend primary care health centres. ${ }^{12,15}$

Measures for the prevention of cardiovascular diseases are often delayed because of the lack of control of the risk factors. ${ }^{16}$ In an attempt to improve this situation, a mixed education programme was designed in the Spanish region of Valencia composed of an internetbased course lasting 1 academic year complemented by face-to-face workshops about cardiovascular skills. The aim of this study was to assess the differences in the record rates of cardiovascular indicators in the medical records of patients attending over a period of 48 months, comparing results between those professionals who did the course and those who did not.

This educational activity formed part of the ESCARVAL project, ${ }^{4}$ and was combined with cross-sectional research to map cardiovascular risk and longitudinal research to obtain prognostic indicators in patients with cardiovascular risk factors and scales of the risk of cardiovascular events for the population of the Valencian Community. ${ }^{4}$

\section{METHOD}

\section{Setting}

The Valencian Health Agency is the organism entrusted with public health care in the Valencian community, covering a population of over 5.5 million people. Primary care is provided at health centres, which have basic attendance units, usually composed of a physician and a nurse who are assigned a quota of patients, 1500 patients at least each unit. This unit can access the centralised computerised patient record system ABUCASIS, and record the patient processes and test results.

The Valencian Community is one of the autonomous regions in Spain with the highest rates of cardiovascular disease and death..$^{17}$ Consequently, the 2005-2009 health plan was designed with the main aim of reducing these rates via a strategic plan. ${ }^{12}$ The ESCARVAL project was created in 2007 to help fulfil this plan by means of a mixed education programme.

\section{Design, population, and data collection}

The study used a quasi-experimental design without random assignment of professionals, as participation was voluntary. It was an educational intervention study in which the intervention group was composed of healthcare professionals (nurses and physicians) who undertook and passed the educational programme, with the control group being composed of all other health professionals in the Valencian Community public health system.

All EHR assigned to participants were analysed by software to assess the cardiovascular indicator records. The results were obtained from the ABUCASIS computerised medical records, a unique, centralised computerised system for ambulatory care in the Valencian Community started in the spring of 2003. The assessment indicators agreed by the scientific committee of the ESCARVAL project and which were indicators of improvements in the quality of health care, were those associated with cardiovascular screening incorporated into the promotion and preventive activities programme of the Spanish Society of Family and Community Medicine in 2007 (PAPPS): 1 screening of blood pressure, basal blood glucose, total cholesterol, and smoking and alcohol habits. Data were also recorded about the prevalence rates of hypertension, dyslipidaemia, and known diabetes determined from the medical records, as well as abdominal circumference, microalbuminuria, and cardiovascular risk calculated with the Systematic Coronary Risk Evaluation (SCORE) tables for countries like Spain la southern European countryl, which have a low cardiovascular risk, as recommended by the guidelines. ${ }^{18}$

The baseline evaluation was undertaken before the educational programme, in December 2006. A longitudinal prospective study was made of the EHR every 6 months over eight periods, with the last of these taking place between 1 July and 31 December 2010.

\section{Educational intervention}

The mixed education programme consisted of 1 year of tutored, personalised online training, with two face-to-face workshops of 4 hours at the start and end of the training. The workshops took place in each of the 23 health departments of the Valencian Community and were given by primary care professionals (nurses and physicians). 
The online training took place at the virtual campus of the Valencian School of Health Studies, belonging to the Valencian Community Health Ministry. The training course was divided into three modules:

- cardiovascular clinical skills module covering diagnostic procedures, use of cardiovascular risk charts, treatments, therapeutic inertia, and compliance;

- a lifestyles and dietary and hygienic measures module including recommendations in prevention and health promotion based on the Prevention Programme (PAPPS) of semFYC, and;

- a cardiovascular research skills module covering data collection procedures, study designs, data analysis, and use of reviews and meta-analysis in clinical practice.

Each module lasted 10 weeks and the assessment was done for the next 2 weeks. The modules included text units and online discussion forums tutored individually by specialists in cardiovascular disease. The first face-to-face workshop covered the development skills to predict the cardiovascular risk and the last workshop was about the proper use of computerised medical records (ABUCASIS).

\section{Data analysis}

A descriptive analysis was completed on the study variables. The qualitative variables are expressed with their absolute value and $95 \%$ confidence intervals (Cls). To determine the temporal evolution of the different values during the follow-up period, linear regression equations were done for each

\section{Table 1. Number of medical histories assigned to participating and non-participating professionals at the different times}

\begin{tabular}{|c|c|c|c|c|c|c|}
\hline \multirow[b]{2}{*}{ Date } & \multicolumn{3}{|c|}{ Intervention group } & \multicolumn{3}{|c|}{ Control group } \\
\hline & $\mathrm{PCU}^{\mathrm{a}}$ & Histories & Mean & $\mathrm{PCU}^{\mathrm{a}}$ & Histories & Mean \\
\hline To Dec 06 & 380 & 490921 & 1291.90 & 2934 & 2992648 & 1019.99 \\
\hline Jan 07-Jun 07 & 380 & 497137 & 1308.26 & 2.934 & 3030738 & 1032.97 \\
\hline Jul 07-Dec 07 & 379 & 559736 & 1476.88 & 2.987 & 3602771 & 1206.15 \\
\hline Jan 08-Jun 08 & 369 & 587652 & 1592.55 & 2821 & 4173479 & 1479.43 \\
\hline Jul 08-Dec 08 & 369 & 591228 & 1602.24 & 2846 & 4198673 & 1475.29 \\
\hline Jan 09-Jun 09 & 369 & 594705 & 1611.67 & 2868 & 4223606 & 1472.67 \\
\hline Jul 09-Dec 09 & 369 & 604634 & 1638.57 & 2934 & 4604643 & 1569.41 \\
\hline Jan 10-Jun 10 & 368 & 601867 & 1635.51 & 3004 & 4763532 & 1585.73 \\
\hline Jul 10-Dec 10 & 372 & 610931 & 1642.29 & 3055 & 4925712 & 1612.34 \\
\hline
\end{tabular}

$P C U=$ primary care unit (nurse and physician). of the variables recorded in the intervention group and in the control group, estimating the slopes in each equation. To determine whether the growth rates differed between the two groups during the follow-up period, the presence or otherwise of significant differences between the groups was determined. ${ }^{19}$ Statistical significance was assessed at $P<0.05$ and $95 \% \mathrm{Cl}$.

For clinical significance, four measures of association were calculated: relative risk $(R R)$, absolute risk reduction (ARR), relative risk reduction (RRR), and number-neededto-treat (NNT). ${ }^{20}$ NNT was adapted for this study and called NNA number-needed-toattend'. The calculations were made using the SPSS statistical package program. (version 15.0.1).

\section{RESULTS}

A total of 1411 healthcare professionals from different health centres in the Valencian Community enrolled voluntarily in the education programme between March and June 2007. Of these, 470 healthcare professionals abandoned the programme between the first face-to-face workshop and registration in the first module, resulting in 941 professionals registering and starting the online course. From these, 686 passed the three modules at the first attempt and 78 passed at the second attempt. Thus, 735 obtained accreditation, of whom 380 where primary care physicians and 355 nurses. The control group was composed of the other healthcare professionals, a total of 2934 physicians and nurses.

Table 1 shows the number of medical histories assigned to professionals who undertook and passed the educational programme (participating professionals) and those assigned to clinicians who did not do the training (non-participating professionals) at different times during the follow-up. The mean medical histories per participant ranged from 1020 to 1642 . Medical histories from patients who were seen by different doctors during the study were excluded.

The prevalence rates of recording of hypertension, dyslipidaemia, and diabetes during the follow-up in the intervention and control groups are shown in Figure 1. The prevalence rates for recording of blood pressure, total cholesterol, basal blood glucose, and microalbuminuria lall measured in people with no diagnosis of hypertension, diabetes, or dyslipidaemia) according to group are shown in Figure 2. Figure 3 shows the recording of smoking habit, alcohol consumption, SCORE, and the abdominal circumference in the 

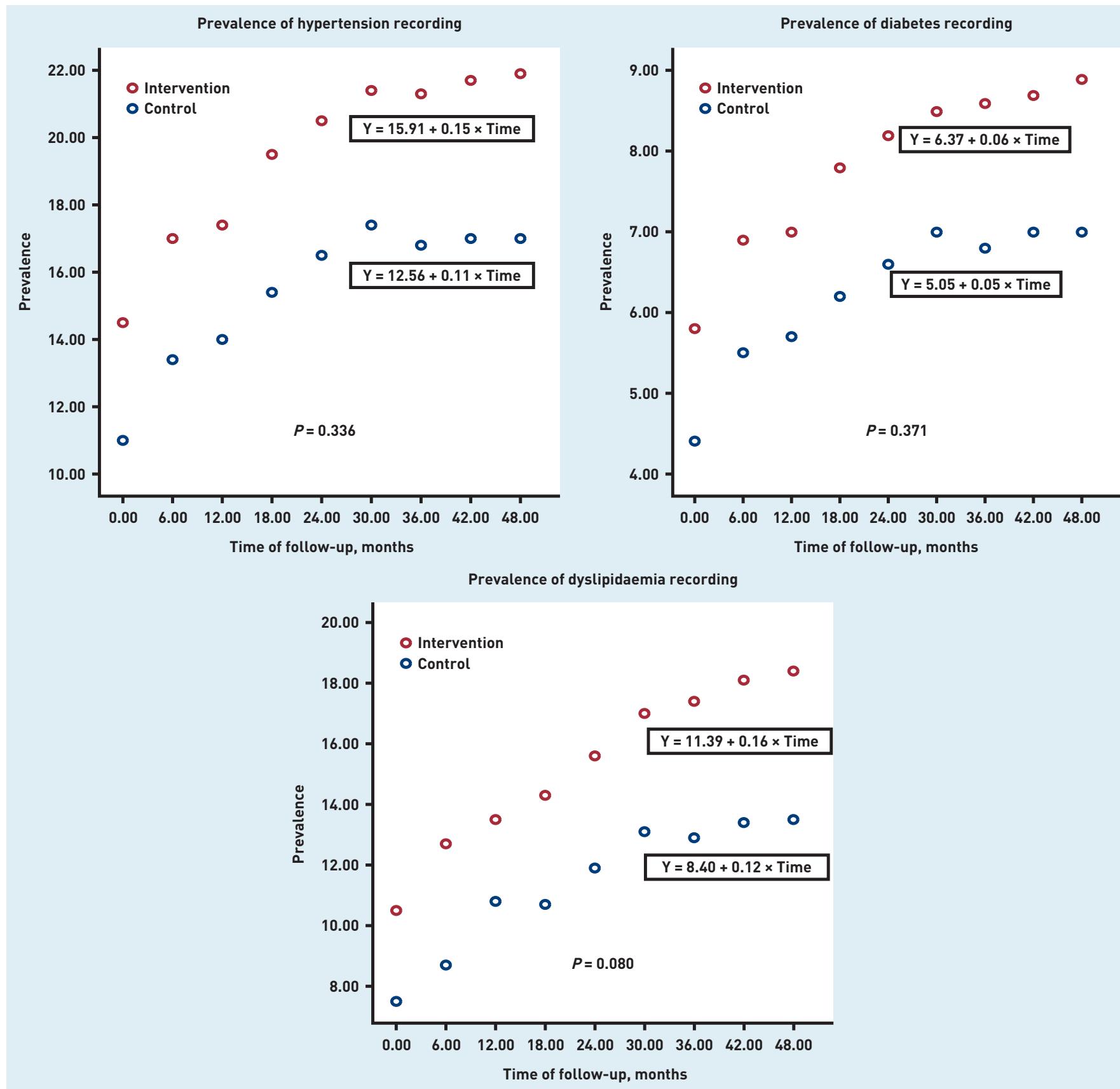

Figure 1. Hypertension, dyslipidaemia, and diabetes recording in the medical records during the follow-up in the intervention and control groups. intervention and control groups throughout the follow-up period. In all cases the regression equation slope was estimated and study of the statistical significance between the results in both groups during the follow-up showed them to be significantly different from $0(P<0.001)$ for the recording of cholesterol, basal blood glucose, microalbuminuria, smoking, alcohol consumption, SCORE, and abdominal circumference.

The prevalence rates of cardiovascular information recording at baseline before the educational programme and at the end of the follow-up period for both groups are shown in Table 2.

To determine the association between the educational intervention and the differences in recording rates, the measures of association were calculated (Table 3).

\section{DISCUSSION}

\section{Summary}

Many countries have achieved an important reduction in cardiovascular death with a better understanding and control of the associated risk factors. ${ }^{21}$ This study 


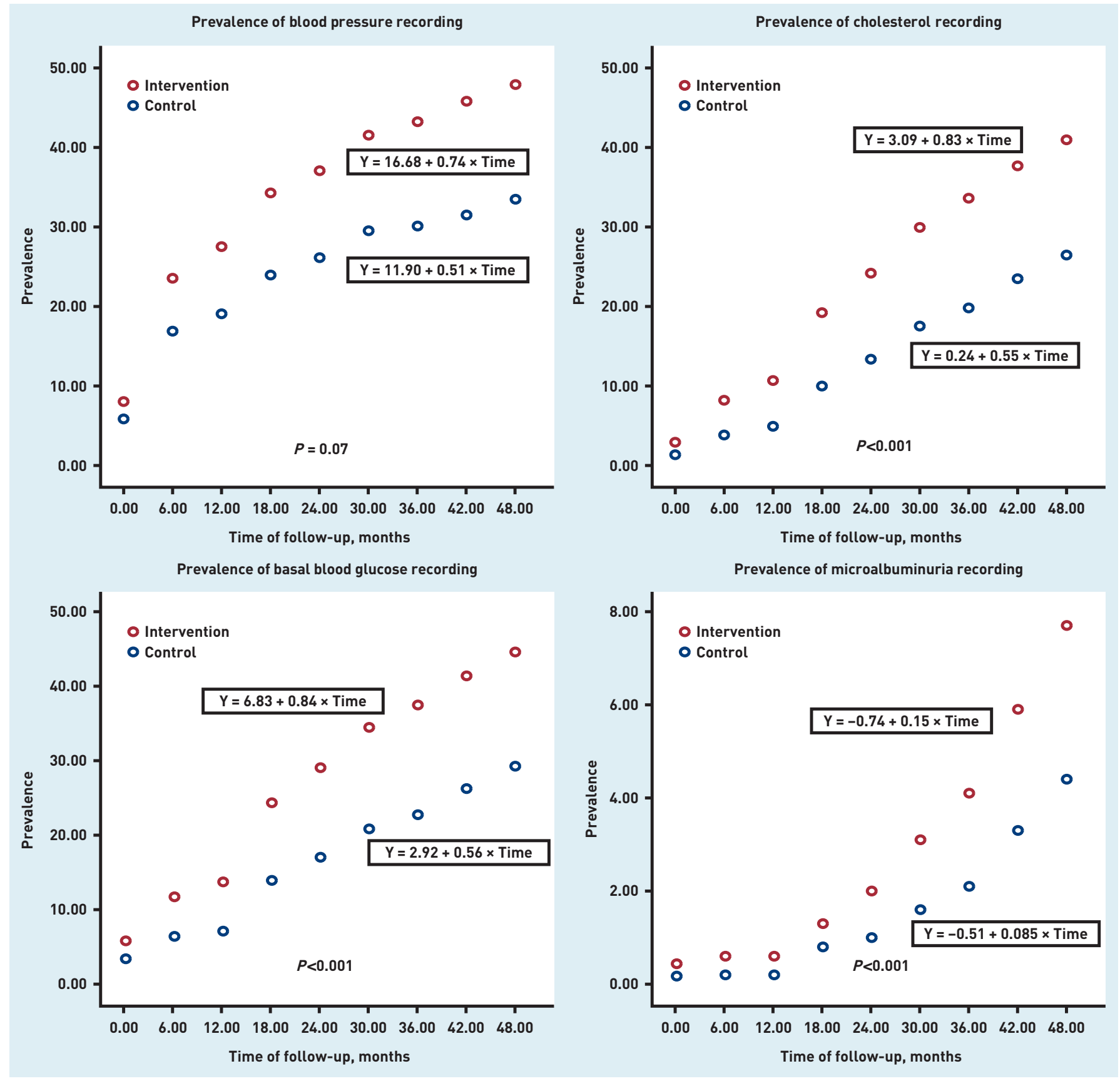

Figure 2. The blood pressure, total cholesterol, basal blood glucose, and microalbuminuria recording in medical records during the follow-up in the intervention and control groups. demonstrated the efficacy of an educational intervention to improve cardiovascular screening by primary health professionals.

The prevalence rates of cardiovascular risk factor records were higher in the intervention group than in the control group at all times during the follow-up of this study. In all cases the regression equation slope was greater in the intervention group than in the control group, and the study of the statistical significance between the values in both groups during the follow-up showed them to be significantly different from 0 for recording of cholesterol, basal blood glucose, microalbuminuria, smoking, alcohol consumption, SCORE, and abdominal circumference, meaning that the growth rates differed between groups during the follow-up, independent of the baseline status.

Regarding clinical significance, Table 3 shows the measures of association where RR ranged from 1.27 for diagnosis of diabetes to 2.77 for recording the SCORE value, meaning that the intervention group was 2.77 times more likely to record the SCORE value than the control group. The RRR ranged from $26.7 \%$ for diagnosis 


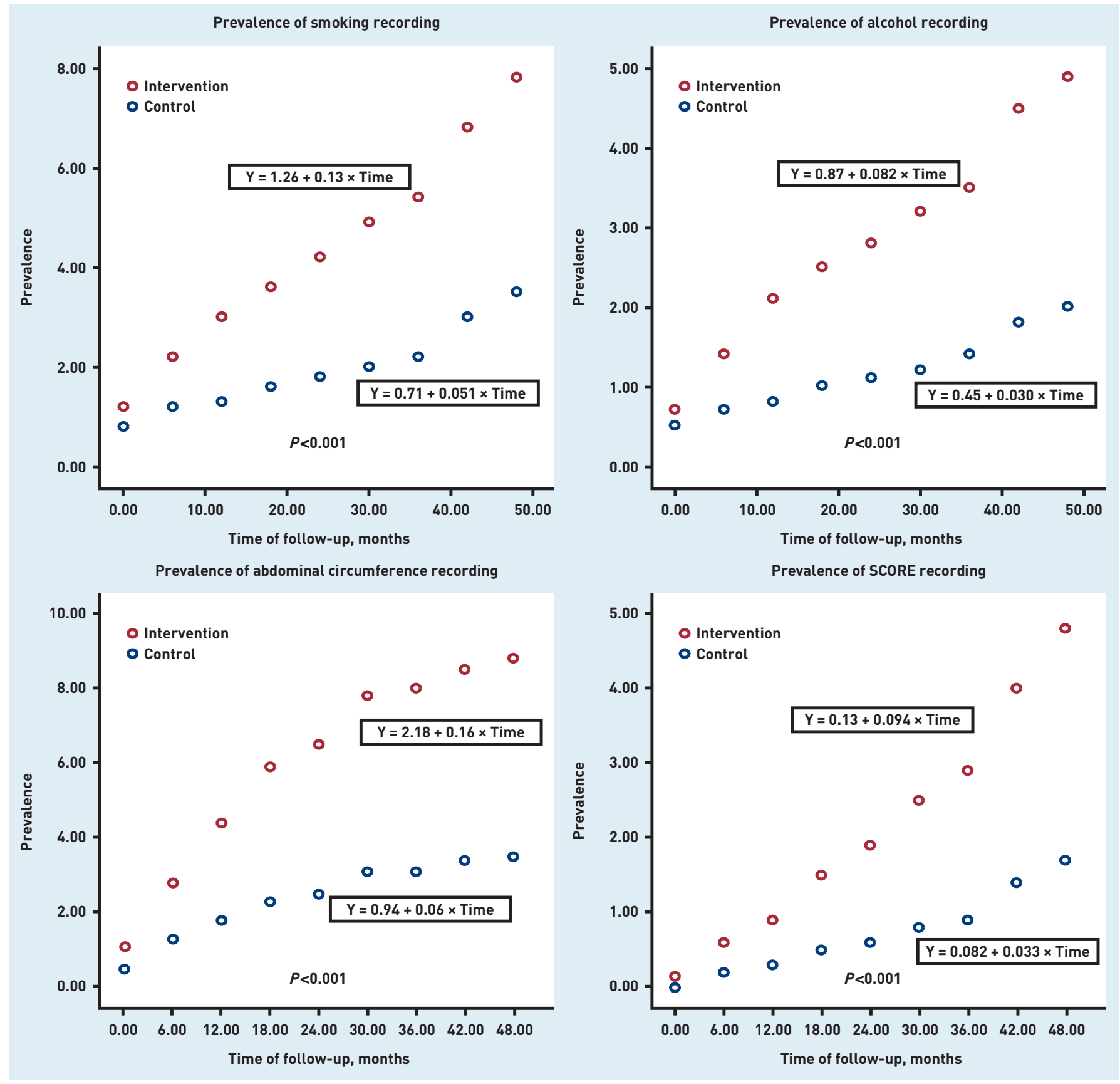

Figure 3. Smoking habit, alcohol consumption, SCORE, and the abdominal circumference recording in the medical records during the follow-up in the intervention and control groups. of diabetes to $177.1 \%$ for recording the SCORE value, which showed how much more the intervention group recorded compared with the control group for the various study variables, that is, the number of cases of diabetes recorded by physicians who completed the course was $26.7 \%$ times greater than the number of cases of diabetes recorded by the physicians who did not complete the course.

The ARR ranged from $1.87 \%$ for the diagnosis of diabetes mellitus to $15.27 \%$ for the recording of basal blood glucose. Thus, for each 100 patients, a physician who did the training programme recorded the basal blood glucose 15.27 times more than a physician who did not do the training. The highest NNA value, 54, corresponded to the diagnosis of diabetes mellitus, that is for each of the 54 patients, a physician who completed the course recorded one more case of diabetes than a physician who did not complete the course.

All the parameters studied showed a clearly beneficial effect in favour of the educational intervention at the end of the follow-up period that was significant and clinically relevant. 
Table 2. Prevalence rates of cardiovascular information recording at baseline and at the end of the follow-up for both groups

\begin{tabular}{|c|c|c|c|c|c|c|c|c|c|c|c|c|}
\hline & \multicolumn{11}{|c|}{ Prevalence rates of cardiovascular information recording, \% } \\
\hline & & HTA & Dys & DM & BP & Cho & BBG & Smk & Alc & SCORE & Malb & AC \\
\hline \multirow{2}{*}{$\begin{array}{l}\text { Before training } \\
\text { programme }\end{array}$} & Intervention group & 14.5 & 10.5 & 5.8 & 8.0 & 2.6 & 5.8 & 1.2 & 0.7 & 0.1 & 0.4 & 1.1 \\
\hline & Control group & 11.0 & 7.5 & 4.4 & 5.8 & 1.3 & 3.4 & 0.8 & 0.5 & 0.0 & 0.2 & 0.5 \\
\hline \multirow{2}{*}{$\begin{array}{l}\text { After training } \\
\text { programme }\end{array}$} & Intervention group & 21.9 & 18.4 & 8.9 & 48.1 & 41.2 & 44.5 & 7.8 & 4.9 & 4.8 & 7.7 & 8.8 \\
\hline & Control group & 17.0 & 13.5 & 7.0 & 33.6 & 26.6 & 29.2 & 3.5 & 2.0 & 1.7 & 4.4 & 3.5 \\
\hline
\end{tabular}

$A C=$ abdominal circumference. $A l c=$ alcohol. $B B G=$ basal blood glucose. $B P=$ blood pressure. Cho $=$ cholesterol. DM = diabetes. Dys $=$ dyslipidaemia. $H T A=$ hypertension.

Malb = microalbuminuria. SCORE = Systematic Coronary Risk Evaluation. Smk = smoking

\begin{abstract}
Strengths and limitations
The present study is strengthened by its methodology which allowed comparative estimations between the intervention and control groups. In addition, calculating the linear regression equation slopes minimised the possible selection bias with respect to the baseline situation. Of note, too, is the important sample size, as the study included $99 \%$ of all medical histories, almost 6 million people in the whole autonomous community, in addition to which the data were collected from a single, homogeneous, anonymous, computerbased system. This enabled measurement of the efficacy of the intervention at nine different times during the follow-up period and improved the facility to participate in the course. As attendants were unaware measurements would be made during the follow-up period, the Hawthorne effect was minimised. Finally, this study highlights and promotes the importance of continuing professional development (CPD), and in
\end{abstract}

future it will be determined whether the intervention has an effect not only on the attitudes and practice of the professionals but also on the morbidity and mortality of their patients as this is one of the objectives of the ESCARVAL Project. ${ }^{4}$

The limitations of the study derive from the inherent lack of randomisation, as it is not possible in these types of studies to force the professionals to do the educational course against their will. Differences in the prevalence rates measured at baseline before the intervention could reflect differences between the professionals, as it seems unlikely that the patients were different because the population assigned to the various quotas was similar in the number and percentage of retired and active persons. The control group also tended to experience an increase in recording, which could be caused by the Hawthorne effect and to improvements in the computerised system over the study period. As the details of the professionals

Table 3. Activities assessed 48 months after starting the follow-up.

\begin{tabular}{|c|c|c|c|c|c|c|c|c|c|c|}
\hline \multirow[b]{2}{*}{ Activity } & \multicolumn{2}{|c|}{ Did the training } & \multicolumn{8}{|c|}{ Clinical relevance } \\
\hline & Yes & No & $\mathbf{R R}$ & $95 \% \mathrm{Cl}$ & RRR & $95 \% \mathrm{Cl}$ & ARR & $95 \% \mathrm{Cl}$ & NNA & $95 \% \mathrm{Cl}$ \\
\hline Diagnosis of hypertension & 133821 & 838521 & 1.29 & 1.28 to 1.29 & 28.75 & 28.09 to 29.35 & 4.88 & 4.77 to 4.99 & 21 & 21 to 21 \\
\hline Diagnosis of dyslipidaemia & 112182 & 663377 & 1.36 & 1.36 to 1.37 & 36.35 & 35.56 to 37.13 & 4.89 & 4.79 to 5.00 & 21 & 21 to 21 \\
\hline Diagnosis of diabetes mellitus & 54120 & 344369 & 1.27 & 1.26 to 1.28 & 26.71 & 25.65 to 27.82 & 1.87 & 1.79 to 1.94 & 54 & 52 to 56 \\
\hline Record abdominal circumference & 53797 & 174365 & 2.49 & 2.46 to 2.51 & 148.89 & 146.51 to 151.19 & 5.27 & 5.19 to 5.34 & 19 & 19 to 20 \\
\hline Record the SCORE & 29596 & 86116 & 2.77 & 2.74 to 2.81 & 177.15 & 173.59 to 180.78 & 3.10 & 3.04 to 3.15 & 33 & 32 to 33 \\
\hline Record microalbuminuria & 47036 & 214791 & 1.77 & 1.75 to 1.78 & 76.71 & 75.01 to 78.44 & 3.34 & 3.27 to 3.41 & 30 & 30 to 31 \\
\hline Record blood pressure & 293634 & 1654710 & 1.43 & 1.43 to 1.43 & 43.19 & 42.75 to 43.55 & 14.47 & 14.34 to 14.60 & 7 & 7 to 7 \\
\hline Record basal blood glucose & 271572 & 1437558 & 1.52 & 1.52 to 1.53 & 52.35 & 51.81 to 52.80 & 15.27 & 15.14 to 15.40 & 7 & 7 to 7 \\
\hline Record total cholesterol & 251431 & 1310772 & 1.55 & 1.54 to 1.55 & 54.71 & 54.19 to 55.23 & 14.54 & 14.42 to 14.67 & 7 & 7 to 7 \\
\hline Record smoking & 47915 & 170478 & 2.27 & 2.24 to 2.29 & 126.69 & 124.44 to 128.88 & 4.38 & 4.31 to 4.45 & 23 & 23 to 24 \\
\hline Record alcohol & 29721 & 98166 & 2.44 & 2.41 to 2.47 & 144.15 & 141.00 to 147.24 & 2.87 & 2.82 to 2.93 & 35 & 35 to 36 \\
\hline
\end{tabular}

$A R R=$ absolute risk reduction. $N N A=$ number-needed-to-attend. $R R=$ relative risk. $R R R=$ relative risk reduction. 
involved were encrypted and therefore anonymous, it cannot be determined whether there existed differences between the intervention and control groups concerning sociodemographic and educational characteristics. The motivation of the participating professionals may introduce a bias but multivariate analysis was used. The authors also acknowledge that a minimal percentage $(<5 \%)$ of the nurses who did the course worked with a physician who did not do the course, which could have improved the results in the control group. In addition, there was not 100\% physician-nurse team participation in the intervention group, which could lead to underestimation of efficacy of the educational course as measured from the results.

\section{Comparison with existing literature}

In view of the wide variety of training techniques and objectives of studies that assess the effect of an educational programme, results are difficult to compare. There are studies that suggest face-toface training is comparable with online training, ${ }^{6,7,22,23}$ although many indicate that the computer platforms need to be improved as participants encountered difficulty using them. ${ }^{24,25}$ Nevertheless, most studies found an increase in knowledge and satisfaction when approaching the problems dealt with in the training courses. ${ }^{9}$ Educational courses, independently of the technique used, improve control of hypertension, dyslipidaemia, and diabetes, as well as behaviour, particularly concerning the prevention of events in patients with a high cardiovascular risk. ${ }^{26}$ Finally, some authors conclude that internet training is efficient in different fields. ${ }^{27,28}$

\section{Implications for practice}

A training programme for primary care professionals increased the prevalence rates of cardiovascular risk factor records. The improvement was clinically significant and relevant. Educational strategies should be continuous and constant, and a good solution would be to introduce reminders on the EHR or any electronic systems used by professionals.

\section{Funding}

This research received no specific grant from any funding agency in the public, commercial, or not-for-profit sectors.

\section{Ethical approval}

The study was approved by the ethics committee of the Public Health General Office in 2007.

\section{Provenance}

Freely submitted; externally peer reviewed.

\section{Competing interests}

The authors have declared no competing interests.

\section{Acknowledgements}

We are grateful to Conselleria de Sanidad for allowing access to the ABUCASIS system and Antonio Fernandez who provided technical support during the study period.

\section{Discuss this article}

Contribute and read comments about this article: bjgp.org/letters 


\section{REFERENCES}

1. Maiques Galán A, Brotons Cuixart C, Villar Álvarez F, et al. Grupo de Prevención Cardiovascular del PAPPS. Recomendaciones preventivas cardiovasculares. [Cardiovascular Prevention Team (PAPPS) Recommendations for cardiovascular prevention.] Aten Primaria 2012; 44 Suppl 1: 3-15.

2. Cabana MD, Rand CS, Powe NR, et al. Why don't physicians follow clinical practice guidelines? A framework for improvement. JAMA 1999; 282(15): 1458-1465.

3. Mancia G, Laurent, S, Agabiti-Rosei E, et al. Reappraisal of European guidelines on hypertension management: a European Society of Hypertension Task Force document. J Hypertens 2009; 27: 2121-2158.

4. Gil-Guillen V, Orozco-Beltran D, Redon J, et al. Rationale and methods of the cardiometabolic Valencian study (Escarval-Risk) for validation of risk scales in Mediterranean patients with hypertension, diabetes or dyslipidemia. BMC Public Health 2010; 10: 717.

5. Ryan G, Lyon P, Kumar K, et al. Online CME: an effective alternative to face-toface delivery. Med Teach 2007; 29(8): e251-257.

6. Cook DA, Levinson AJ, Garside S, et al. Internet-based learning in the health professions: a meta-analysis. JAMA 2008; 300(10): 1181-11968.

7. Fordis M, King JE, Ballantyne CM, et al. Comparison of the instructional efficacy of Internet-based CME with live interactive CME workshops: a randomized controlled trial. JAMA 2005; 294(9): 1043-1051.

8. Geissbuhler A, Bagayoko CO, Ly O. The RAFT network: 5 years of distance continuing medical education and tele-consultations over the Internet in French-speaking Africa. Int J Med Inform 2007; 76: 351-356.

9. Kulier R, Hadley J, Weinbrenner S, et al. Harmonising evidence-based medicine teaching: a study of the outcomes of e-learning in five European countries. BMC Med Educ 2008; 8: 27.

10. Gil-Guillen V Carratala-Munuera MC, Orozco-Beltran D, et al. PhD programmes in Family Medicine: A new university service for primary care doctors. Aten Primaria 2009; 41(3): 163-167.

11. World Health Organization. The top 10 causes of death. http://who.int/ mediacentre/factsheets/fs310/en/index.html (accessed 9 Nov 2014).

12. Plan de salud de la Comunidad Valenciana 2010-2013. [Valencia Regional Health Plan 2010-2013.] http://www.san.gva.es/cas/prof/homeprof.html (accessed 28 Nov 2014).

13. De la Sierra A, Gorostidi M, Marín R, et al. Evaluación y tratamiento de la hipertensión arterial en España. Documento de consenso. [Evaluation and treatment of hypertension in Spain.] Med Clin (Barc) 2008; 131(3): 104-116.

14. American Diabetes Association. Standards of medical care in diabetes - 2012. Diabetes Care 2012; 35 Suppl 1: S11-63.
15. Pedrera Carbonell V, Gil Guillen V, Orozco Beltran, et al. Características de la demanda sanitaria en las consultas de medicina de familia de un área de salud de la Comunidad Valenciana. [Features of health demand in family medicine consultation in the region of Valencia]. Aten Primaria 2005; 35(2): 82-88.

16. Alonso F, Segovia J, Heras M, Bermejo J. Prevención cardiovascular: Siempre demasiado tarde. [Cardiovascular prevention: is it so late?] Rev Esp Cardiol 2008; 61(3): 291-298

17. Villar Álvarez F, Banegas Banegas JR, de Mata Donado Campos J, Rodríguez Artalejo F. Las enfermedades cardiovasculares y sus factores de riesgo en España: hechos y cifras. Informe de la Sociedad Española de Arteriosclerosis 2007. [Cardiovascular diseases and risk factors in Spain: facts and figures. Spanish Society of Arteriosclerosis Report, 2007.] Ed. Visto Bueno Equipo Creativo, S.L., Madrid, 2007

18. Sans S, Fitzgerald AP, Royo D, et al. Calibración de la tabla SCORE de riesgo cardiovascular para España. [Calibrating the SCORE Cardiovascular Risk Chart for Use in Spain.] Rev Esp Cardiol 2007; 60: 476-485.

19. Sklo M, Nieto FJ. Epidemiology: beyond the basics. Gaithersburg: Md: Aspen Publications, 2000

20. Cook RJ, Sackett DL. The number needed to treat: a clinically useful measure of treatment effect. BMJ 1995; 310(6977): 452-454.

21. Kiessling A, Lewitt M, Henriksson P. Case-based training of evidence-based clinical practice in primary care and decreased mortality in patients with coronary heart disease. Ann Fam Med 2011; 9(3): 211-218.

22. Perkins, GD, Fullerton JN, Davis-Gomez N, et al. The effect of pre-course e-learning prior to advanced life support training: a randomised controlled trial. Resuscitation 2010; 81(7): 877-881.

23. Cullen RJ. In search of evidence: family practitioners' use of the internet for clinical information. J Med Libr Assoc 2002; 90(4): 370-379.

24. Pelayo $M$, Cebrián D, Areosa $A$, et al. Effects of online palliative care training on knowledge, attitude and satisfaction of primary care physicians. BMC Fam Pract 2011; 12: 37

25. Gilmour JA, Scott SD, Huntington N. Nurses and Internet health information: a questionnaire survey. J Adv Nurs 2008; 61(1): 1928.

26. Allaire BT, Trogdon JG, Egan BM, et al. Measuring the impact of a continuing medical education program on patient blood pressure. Clin Hypertens (Greenwich) 2011; 13: 517-522.

27. Marsh-Tootle WL, McGwin G, Kohler CL, et al. Efficacy of a web-based intervention to improve and sustain knowledge and screening for amblyopia in primary care settings. Invest Ophthalmol Vis Sci 2011; 52(10): 7160-7167.

28. Knapp H, Chan K, Anaya HD, Goetz MB. Interactive internet-based clinical education: an efficient and cost-savings approach to point-of-care test training. Telemed J E Health 2011; 17(5): 335-340. 